\title{
A SIMULATION MODEL OF RIVER ICE COVER THERMODYNAMICS
}

\author{
Gordon M. Greene
}

National Oceanic and Atmospheric Administration, Great Lakes Environmental Research Laboratory, 2300 Washtenaw Avenue, Ann Arbor, Michigen 48104 (U.S.A.)

\author{
and Samuel I. Outcalt
}

Department of Geological Sciences, The University of Michigan, Ann Arbor, Michigan 48109 (U.S.A.)

(Received September 11, 1984; accepted in revised form October 5, 1984)

\section{ABSTRACT}

A model of ice cover thermodynamics was used to simulate ice growth and decay along the international section of the St. Lawrence River for winter 198081. This winter was chosen because of the exceptionally cold weather in December and January, and because of the abnormally warm air temperatures during the second half of February. At the air-ice interface, the model computes the surface energy transfer components and a resulting equilibrium surface temperature. At the lower boundary, an empirical algorith simulates the turbulent transfer of heat from the water. Within the ice, and implicit numerical solution to the general heat diffusion equation is used, permitting stable solutions for a variety of time intervals and node distances within the model. The model was used to simulate ice growth and decay at five sites characterized by their flow velocity, the date of ice-cover formation, and the water temperature regime. The model adequately represented growth rates at all five sites, but produced decay rates slower than those observed. Simulated breakup was 1-7 days later than observed, presumably because mechanical weakening of the ice was not taken into consideration. During the growth period, the model is far more sensitive to the values assigned to ice properties than it is to the error range in the meteorological variables. During the breakup period, the most sensitive boundary variable is water temperature.

\section{INTRODUCTION}

The purpose of this paper is to describe the construction and application of a one-dimensional thermodynamic model for simulating ice cover growth and decay on rivers. While Ashton (1978) has pointed out that the significant events in river-ice cover chronology occur in abrupt transitions from one steady-state condition to another, a thermal model that excludes hydraulic or mechanical forces serves a number of uses. The primary use described here is as a tool for investigating the sensitivity of the ice cover to various heat-transfer processes, and to the values assigned to a variety of model properties and boundary conditions.

In addition, the model has application as a simulator of ice growth and decay on small lakes or regulated rivers, where hydraulic forces are minimal or well controlled. The latter portion of the paper describes such an application to five sites on the St. Lawrence River above the hydropower complex at Cornwall, Ontario. Finally, the model provides a means of estimating both the temperature gradient within the snow and ice and the amount of absorbed shortwave radiation.

Thermodynamic models of river ice sheets are not new, but most work has concentrated on the turbulent transfer of heat from the river to the underside of the ice (e.g. Baines, 1961; Ashton, 1973) with little emphasis on heat transfer within the ice cover 
and at the surface boundary. Calkins (1979), for example, used a simple molecular conduction model with a linear temperature gradient to simulate the effect of frazil ice porosity on ice-cover growth rates.

Models of sea or lake ice are more likely to emphasize the surface and internal processes. Wake and Rumer (1979) applied a two-dimensional model to Lake Erie, computing an equilibrium surface temperature from energy balance considerations, and conducting heat within the ice along a linear temperature gradient. More closely related to the work reported here is a one-dimensional model of sea ice thermodynamics described by Maykut and Untersteiner (1971). Their model simulates heat transfer below, within, and above the ice-snow cover; allows shortwave radiation to be absorbed within the ice layer; and allows nonlinear temperature gradients to develop.

A much simpler approach to simulating ice growth and decay in rivers has recently been developed by Shen and Yapa (1983). They have expanded the degree-day approach to ice growth to include an empirical decay function. They tested the model for 10 sites along the St. Lawrence River over nine winter seasons.

The model presented here couples a simple algorithm for simulating the turbulent transfer of heat from the river to the ice base with surface energy budget simulation and two different algorithms for determining the rate of heat transfer through the ice and snow. The first approach assumes the molecular conduction of heat along a linear temperature gradient. In the second approach, numerical solutions are employed, based on the implicit temperature diffusion scheme described by Outcalt et al. (1975). The approach permits the model to couple a Beer's law approximation of the internal absorption of shortwave radiation to a nonlinear thermal profile evolution.

Inputs to the model are daily values for air temperature, dew-point temperature, wind speed, incident global shortwave radiation, and water temperature. Atmospheric pressure and water velocity beneath the ice cover are held constant. Observed snow thicknesses on the river ice are inserted as available (every 7 days for the St. Lawrence River). It is also necessary to identify the date of maximum ice cover thickness. In return, the model simulates daily values for surface temperature, components of the surface energy budget, ice thickness, and temperature profiles within the snow and ice cover.

\section{DESCRIPTION OF THE MODEL}

A cross section of the ice cover (Fig. 1) shows the layers that control the transfer of heat from the river to the atmosphere and the energy fluxes that are considered within the model. The snow layer may be absent during any portion of the ice season, thus allowing shortwave radiation to penetrate the ice surface.

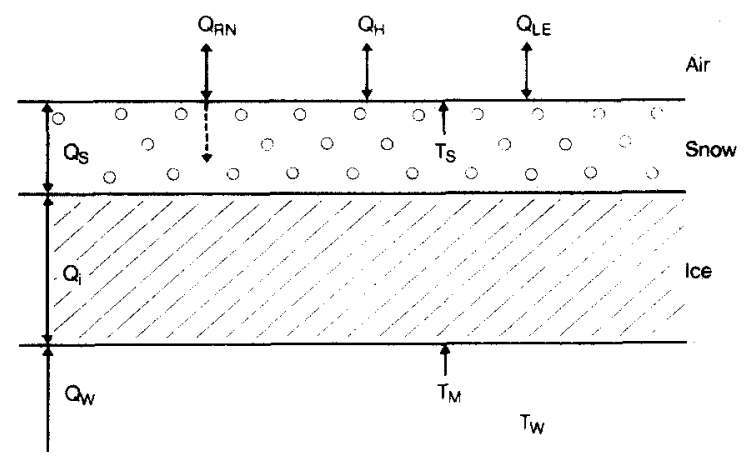

Water

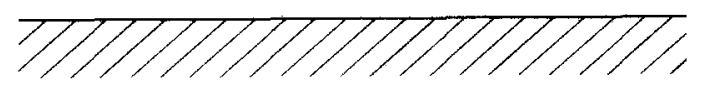

Fig. 1. Vertical section through river ice showing energy fluxes during growth period.

A number of assumptions simplify the simulation of growth and decay. Simulation starts once a solid ice cover has formed. Snow-ice formation is not considered; hence, simulated growth can only occur at the base of the ice layer. The temperature at the water-ice interface is assumed to be $0.0^{\circ} \mathrm{C}$ and the surface temperature $\left(T_{\S}\right)$ is a derived value. Simulated ice decay takes place at the base of the ice layer, and also at the surface during those periods when the surface temperature is $0^{\circ} \mathrm{C}$. Ice and snow properties, such as density, are considered to be constant and uniform throughout each layer. In addition, the flux 
of heat out of the ice is assumed equal to the flux entering the lower surface of the snow.

The simulation model is based on a set of equations that defines the energy fluxes within the snow and ice layers and the mass balances at the boundaries of the snow and the ice cover. The governing equation at the lower ice boundary relates the change in ice thickness to the relative magnitudes of the flux of heat at the lower surface of the ice cover, $Q_{\mathrm{i}}\left(W \mathrm{~m}^{-2}\right)$, and the flux of heat from the water to the ice, $Q_{\mathrm{W}}$ $\left(W \mathrm{~m}^{-2}\right)$.

$Q_{\mathrm{i}}-Q_{\mathrm{w}}=\rho_{\mathrm{i}} \lambda\left(\mathrm{d} Z_{\mathrm{i}} / \mathrm{d} t\right)$,

where $\rho_{\mathrm{i}}$ is ice density $\left(\mathrm{kg} \mathrm{m}^{-3}\right), \lambda$ is the latent heat of fusion $\left(\mathrm{J} \mathrm{kg}^{-1}\right), Z_{\mathrm{i}}$ represents ice-cover thickness (m), and $t$ is time (s). By assuming a steady-state partitioning of energy fluxes at the snow or ice surface, one can calculate the upper boundary condition for energy flux as follows:

$Q_{\mathrm{i}}\left(\right.$ or $\left.Q_{\mathrm{s}}\right)=-\left(Q_{\mathrm{m}}+Q_{\mathrm{h}}+Q_{\mathrm{le}}\right)$,

where $Q_{\mathrm{m}}$ is the net radiation flux $\left(\mathrm{W} \mathrm{m}^{-2}\right), Q_{\mathrm{h}}$ is the sensible heat flux to the air $\left(\mathrm{W} \mathrm{m}^{-2}\right)$, and $Q_{\mathrm{le}}$ is the latent heat flux to the air $\left(\mathrm{W} \mathrm{m}^{-2}\right)$.

Heat transfer from the river to the base of the ice sheet is computed with an empirical relation that calculates the rate of heat transfer from a fluid to the boundaries of a closed conduit (Ashton, 1973).

$Q_{\mathrm{w}} R /\left(K_{\mathrm{w}}\left(T_{\mathrm{w}}-T_{\mathrm{m}}\right)\right)=B \operatorname{Re}^{0.8} \operatorname{Pr}^{0.4}$

By computing expected values of the Reynolds (Re) and Prandtl (Pr) numbers at $0^{\circ} \mathrm{C}$ and by equating the hydraulic radius, $R$, with half the water depth beneath the ice cover, eqn. (3) can be rearranged to express $Q_{\mathrm{w}}$ as a function of a temperature difference and a heat transfer coefficient, $h_{\mathrm{i}}\left(\mathrm{W} \mathrm{m}^{-2}{ }^{\circ} \mathrm{C}^{-1}\right)$.

$Q_{\mathrm{w}}=\left(T_{\mathrm{w}}-T_{\mathrm{m}}\right) h_{\mathrm{i}}$,

where

$h_{\mathrm{i}}=B_{\mathrm{i}}\left(U_{\mathrm{w}}{ }^{0.8} / Z_{\mathrm{w}}{ }^{0.2}\right)$,

$B_{\mathrm{i}}$ is an empirical constant $\left(\mathrm{W} \mathrm{m}^{-2.6} \mathrm{~s}^{0.8}{ }^{\circ} \mathrm{C}^{-1}\right), U_{\mathrm{w}}$ is water velocity $\left(\mathrm{m} \mathrm{s}^{-1}\right)$, and $Z_{\mathrm{w}}$ is water depth $(\mathrm{m})$.

While it is common in most ice-growth models to assume that the surface temperature is equivalent to the air temperature, there are many atmospheric conditions (e.g. clear, calm weather) under which this is not valid, particularly when working with sub- diumal time steps. By applying a secant algorithm (Beckett and Hurt, 1967) to a set of surface energy balance equations transcendental in surface temperature, it is possible to compute the equilibrium value for $T_{\mathrm{s}}$. Given a time series of incident shortwave radiation and wind velocity, dewpoint temperature, and air temperature at one level above the surface and by making a number of assumptions about surface properties, one can construct the surface energy balance relations as shown in the appendix and outlined below.

$Q_{\mathrm{i}}=f\left(T_{\mathrm{s}}, K_{\mathrm{i}}, Z_{\mathrm{i}}\right)$,

$Q_{\mathrm{rn}}=f\left(T_{\mathrm{s}}, Q_{\mathrm{sw}}, Q_{\mathrm{swc}}, T_{\mathrm{a}}, T_{\mathrm{d}}, A\right)$,

$Q_{\mathrm{h}}=f\left(T_{\mathrm{s}}, T_{\mathrm{a}}, U, Z_{\mathrm{o}}\right)$,

and

$Q_{\mathrm{le}}=f\left(T_{\mathrm{s}}, T_{\mathrm{a}}, T_{\mathrm{d}}, U, Z_{\mathrm{o}}\right)$,

where $Q_{\mathrm{sw}}$ represents the incident shortwave radiation flux $\left(\mathrm{W} \mathrm{m}^{-2}\right), Q_{\text {swc }}$ is the potential clear sky shortwave radiation flux $\left(\mathrm{W} \mathrm{m}^{-2}\right), T_{\mathrm{a}}$ is air temperature $\left({ }^{\circ} \mathrm{C}\right), T_{\mathrm{d}}$ is dewpoint temperature $\left({ }^{\circ} \mathrm{C}\right), A$ is albedo, $U$ is wind speed $\left(\mathrm{m} \mathrm{s}^{-1}\right)$, and $Z_{\mathrm{o}}$ is the aerodynamic roughness length $(\mathrm{m})$.

When the value for the simulated equilibrium surface temperature is greater than $0^{\circ} \mathrm{C}$, the temperature is reduced to $0^{\circ} \mathrm{C}$ and the excess flux is used for surface ablation.

Steady-state heat flux by molecular conduction through the ice can be defined as

$Q_{\mathrm{i}}=\left(T_{\mathrm{m}}-T_{\mathrm{s}}\right)\left(K_{\mathrm{i}} / Z_{\mathrm{i}}\right)$,

where $T_{\mathrm{m}}$ is the temperature at the base of the ice slab $\left({ }^{\circ} \mathrm{C}\right), T_{\mathrm{s}}$ is the surface temperature $\left({ }^{\circ} \mathrm{C}\right)$, and $K_{\mathrm{i}}$ is thermal conductivity $\left(\mathrm{W} \mathrm{m}^{-1}{ }^{\circ} \mathrm{C}^{-1}\right)$. Three assumptions are implied by this expression for heat flux. The first is that the material is vertically homogeneous in its thermal properties; the second, that there can be no internal sources of heat unless they are uniformly distributed in the vertical dimension; finally, that any change in the surface temperature is reflected immediately by a new linear temperature gradient.

The first assumption can be relaxed if the transfer of heat between layers with different thermal properties is continuous. For example, if a snow layer is present, eqn. (10) becomes 
$Q_{\mathrm{s}}=\left(T_{\mathrm{m}}-T_{\mathrm{s}}\right) /\left[\left(Z_{\mathrm{i}} / K_{\mathrm{i}}\right)+\left(Z_{\mathrm{s}} / K_{\mathrm{s}}\right)\right]$.

A second version of the model was constructed; all elements are identical to those described above except that it allows the development of a nonlinear temperature gradient in the snow and ice layers. In this version, heat transfer is computed by simulating Fickian diffusion of heat. To use the finite-difference method described below, a series of evenly spaced computation nodes was embedded in the simulated ice and snow cover. This method allows the computation of $Q_{\mathrm{i}}$ (or $Q_{\mathrm{s}}$ ) at any level in the snow and ice layers.

The value used in eqn. (2) for the flux leaving the upper surface was computed as a function of the temperature gradient near the surface.

$Q_{\mathrm{i}}=\left(K_{\mathrm{i}} / \Delta Z_{\mathrm{j}}\right)\left(T_{\mathrm{s}-1}-T_{\mathrm{s}}\right)$,

where $\Delta Z_{\mathrm{i}}$ is the distance between nodes and $T_{\mathrm{s}-1}$ is the temperature at the first node below the surface. Likewise, at the lower boundary, the flux $Q_{\mathrm{i}}$ used in eqn. (1) is computed by

$\mathrm{Q}_{\mathrm{i}}=\left(\mathrm{K}_{\mathrm{i}} / \Delta \mathrm{Z}_{\mathrm{i}}\right)\left(\mathrm{T}_{\mathrm{m}}-\mathrm{T}_{\mathrm{m}+1}\right)$,

where $T_{m+1}$ is the temperature at the first node above the lower surface.

Within the snow and ice layers, it is not necessary to compute $Q_{\mathrm{i}}$ directly. Rather, temperature changes are simulated by solving the general one-dimensional heat conduction equation

$\mathrm{d} T / \mathrm{d} t=(K / C)\left(\mathrm{d}^{2} T / \mathrm{d} Z^{2}\right)$.

The implicit scheme to solve the finite-difference form of eqn. (16) is described in Outcalt et al. (1975).

If snow is not present, shortwave radiation will penetrate the surface and alter both the temperature gradient and the cohesion between ice crystals (Ashton, 1984). In order to quantify accurately the attenuation of radiation with depth, one would assign wavelength-specific extinction coefficients and allow for the normal stratification of a river ice cover. In this model, however, the degree of attenuation described by Beer's Law and a constant extinction coefficient is accepted as a first approximation. This is similar to the approach described by Maykut and Untersteiner (1971) and Maguire (1975). The rise in temperature contributed by radiation at any depth is computed as follows: $\mathrm{d} T / \mathrm{d} t=(k / C) Q_{\mathrm{sw}}(1-A) \exp ^{-k z}$,

where $C$ is heat capacity $\left(\mathrm{J} \mathrm{m}^{-3}{ }^{\circ} \mathrm{C}^{-1}\right)$ and $k$ is the extinction coefficient $\left(\mathrm{m}^{-1}\right)$.

The growth or decay during any given period is simulated in the following manner. The model first solves for $T_{\mathrm{s}}$, the equilibrium surface temperature that balances the four energy-balance fluxes. Heat is then allowed to diffuse in the snow and ice layers. The thermal gradient at the base of the ice sheet is used to compute the change in thickness, which necessitates adding or subtracting computation nodes. If nodes are added, they are assigned and initial temperature of $0^{\circ} \mathrm{C}$. Finally, the heat diffusion subroutine is called a second time so that the thermal gradient can come to equilibrium in the thicker or thinner ice sheet.

\section{APPLICATION}

The model has been tested at five sites along the channel of the upper St. Lawrence River for the 1980-81 winter. These are designated F-1, F-2, G-2, H-1, and H-4 in Fig. 2. The 1980-81 winter was chosen as a test season because of the temperature extremes that occurred. The December mean temperature $\left(-11.8^{\circ} \mathrm{C}\right)$ at Massena, N.Y., was the coldest experienced since 1949 , and the January temperature $\left(-14^{\circ} \mathrm{C}\right)$ was the third coldest. February air temperature $\left(-0.4^{\circ} \mathrm{C}\right)$, however, set a record high, exceeding the 30 -year monthly mean by $8^{\circ} \mathrm{C}$ and the previous maximum monthly mean by nearly $4^{\circ} \mathrm{C}$.

Observations of ice events at the five sites were collected from the St. Lawrence Seaway Authority (Cornwall), the St. Lawrence Seaway Development Corporation (Massena) and Ontario Hydro (Cornwall), and are summarized in Table 1. Although maximum ice thickness and river outflow were near normal for the 1980-81 season, freezeup occurred 7-18 days earlier than normal and breakup occurred 9-30 days earlier.

This early breakup was caused for the most part by abnormally warm air during the second half of February. Mean hourly air temperatures in Ogdensburg, N.Y., remained above $0^{\circ} \mathrm{C}$ from noon on February 15 until late February 26, with a high of $14^{\circ} \mathrm{C}$ at midday on February 23 . Nearly $2 \mathrm{~cm}$ of rain 


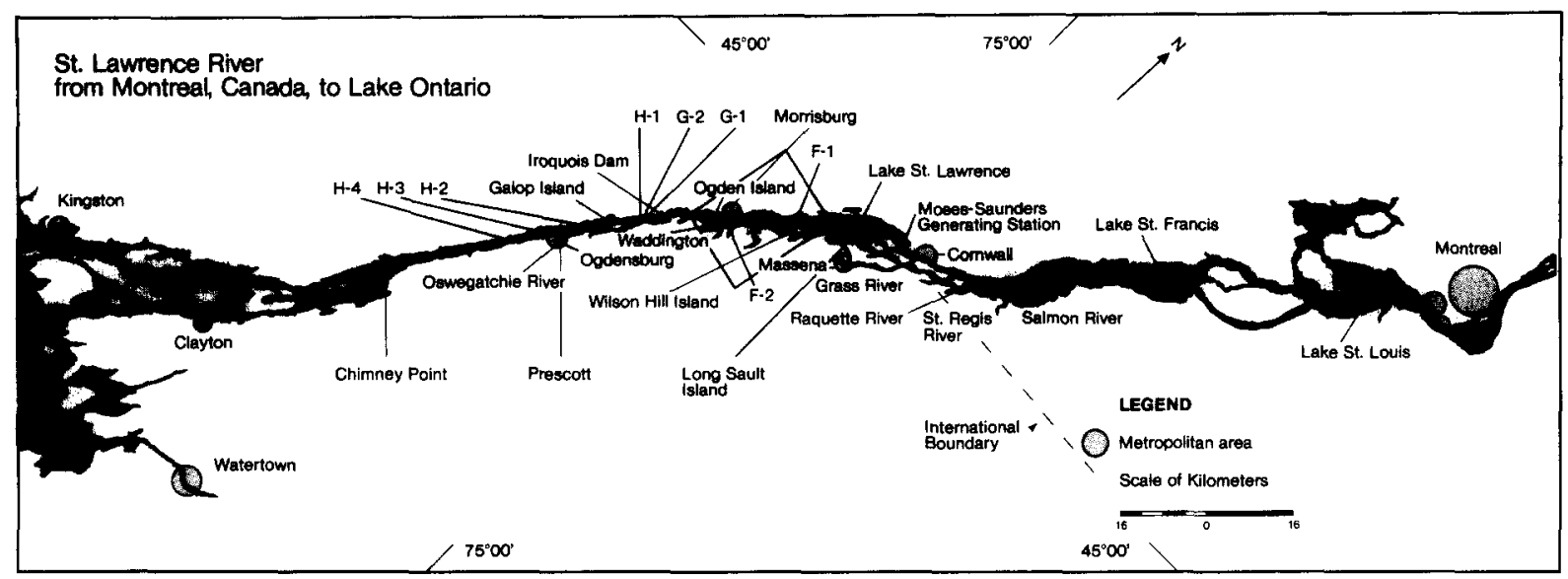

Fig. 2. St. Lawrence River between Montreal, Que., and Lake Ontario. Site numbers refer to ice thickness measuring sites.

\section{TABLE 1}

Comparison of 1980-81 ice event dates with 10-yr mean

\begin{tabular}{lllll}
\hline Site & $\begin{array}{l}\text { 1980-81 date of } \\
\text { ice cover formation }\end{array}$ & $\begin{array}{l}\text { 10-yr mean date } \\
\text { of formaton }\end{array}$ & $\begin{array}{l}\text { 1980-81 period } \\
\text { of breakup }\end{array}$ & $\begin{array}{l}\text { 10-yr mean date } \\
\text { of breakup }\end{array}$ \\
\hline F-1 & Dec. 23 & Jan. 7 & Feb. 17-23 & Mar. 21 \\
F-2 & Dec. 26 & Jan. 13 & Feb. 17-20 & Mar. 5 \\
G-2 & Dec. 23 & Jan. 1 & Mar. 5-17 & Mar. 20 \\
H-1 & Jan. 2 & Jan. 17 & Feb. 13-17 & Mar. 5 \\
H-4 & Jan. 5 & Jan. 12 & Feb. 17-20 & Mar. 8 \\
\hline
\end{tabular}

also fell during this period, speeding the rate of snow ablation and lowering the albedo.

Time series needed to drive the model are those for air temperature, dew-point temperature, wind speed, incident shortwave radiation, and water temperature. The first four were taken from a micrometeorological station operated by the St. Lawrence Seaway Development Corporation. The tower is located on a pier jutting into the St. Lawrence River at Ogdensburg, with the sensors roughly $10 \mathrm{~m}$ above the water surface. A more complete description of the sensors is given in Greene (1981). As noted in Table 2, the greatest distance between a site and the micrometeorological station was $45 \mathrm{~km}$.

Although individual water temperature time series are not available for each site, temperatures are measured once daily at the upstream (Clayton, N.Y.) and downstream (Moses-Saunders Power Dam) ends of the international section of the river (Shen and Yapa, 1982). Therefore, a two-part interpolation scheme was used to assign a daily water temperature to each site, depending on the thermal regime of the river.

During the period between ice cover formation and maximum ice cover thickness, upstream water temperatures were consistently $0.2-1.0^{\circ} \mathrm{C}$ warmer than downstream. Hence, the water temperature at a site was approximated as a function of the upstream temperature and the distance to the upstream sensor, in the form of Newtonian exponential cooling.

$T_{\mathrm{w}}=T_{\mathrm{u}} \exp (-b X)$,

where $X$, the distance in kilometres from Clayton, is a surrogate for elapsed time; $T_{\mathfrak{u}}$ is the water temperature at Clayton; and $b$ is an empirical constant. 
TABLE 2

Characteristics of the five simulation sites

\begin{tabular}{|c|c|c|c|c|}
\hline Site & $\begin{array}{l}\text { Water velocity } \\
\left(\mathrm{m} \mathrm{s}^{-1}\right)\end{array}$ & $\begin{array}{l}\text { Water depth } \\
\text { (m) }\end{array}$ & $\begin{array}{l}\text { Distance from } \\
\text { Clayton }(\mathrm{km})\end{array}$ & $\begin{array}{l}\text { Distance from } \\
\text { Ogdensburg }(\mathrm{km})\end{array}$ \\
\hline$F=1$ & 0.41 & 21.3 & 117 & 45 \\
\hline F-2 & 0.69 & 14.0 & 102 & 29 \\
\hline G-2 & 0.20 & 9.0 & 90 & 18 \\
\hline H-1 & 0.83 & 16.0 & 88 & 17 \\
\hline $\mathrm{H}-4$ & 0.65 & 12.0 & 59 & 13 \\
\hline
\end{tabular}

Water temperatures at a site between the upstream and downstream thermometers were not measured during the 1980-81 winter. However, temperature data from three sites along the river during the 1979_ 80 winter were used to compute a value of 0.056 for $b$.

Once the date of maximum ice thickness is past and an increasing number of reaches are open water, downstream water temperatures are no longer adequately represented by eqn. (16). After this date, therefore, water temperatures at each site were computed by linear interpolation between the upstream and downstream values.

When possible, values used for parameters for the model were chosen from work done on the St. Lawrence River. When this was not possible or when the range of possible values was large, a midrange choice was made. The significance of possible variation in these parameters is discussed in the next section.

Within the simulation model, the five sites were differentiated on the basis of their date of ice-cover formation, the observed (once per week) thickness of snow on the ice at that site, and the four variables listed in Table 2 . Water velocity was computed using the discharge rates and crosssectional area of the river at each site. Water velocity was held constant throughout the season because the flow recorded at the Moses-Saunders Power Dam was relatively constant at $6,796 \mathrm{~m}^{3} \mathrm{~s}^{-1}\left(240,000 \mathrm{ft}^{3} \mathrm{~s}^{-1}\right)$.

Ashton (1979) gives a value of $1,622 \mathrm{~W} \mathrm{~m}^{-2.6} \mathrm{~s}^{0.8}$ ${ }^{\circ} \mathrm{C}^{-1}$ for the parameter $B_{\mathrm{i}}$ used to compute the heat transfer coefficient $\left(h_{\mathrm{i}}\right)$ in eqn. (5), but notes that the value may increase by $50 \%$ if ripples appear during the spring melt period. All runs described in this paper used a constant $B_{\mathbf{i}}$.

Temporally and spatially averaged values for optical properties of ice and snow are poor indicators of actual conditions. In the absence of reasonable algorithms describing how change takes place, constant values were used for mean daily ice and snow albedoes. Because the surface layer is commonly snow ice, a value of 0.45 for ice albedo was chosen (Bolsenga, 1969). Snowfalls occur with a 1- to 2 week frequency; hence, snow albedo was set relatively high at 0.85 . A bulk extinction coefficient of $2.0 \mathrm{~m}^{-1}$ was chosen for the absorption of shortwave radiation within the ice (Maguire, 1975). This value is based on measurements taken between 400 and 700 $\mathrm{nm}$ in ice on the Ottawa River.

An average snow density of $350 \mathrm{~kg} \mathrm{~m}^{-3}$ was selected. Values for snow thermal conductivity and diffusivity were computed as a function of density from relationships reported by Yen (1981). Snow conductivity was $0.307 \mathrm{~W} \mathrm{~m}^{-1}{ }^{\circ} \mathrm{C}^{-1}$ and diffusivity was $4.18 \times 10^{-7} \mathrm{~m}^{2} \mathrm{~m}^{-1}$. A mid-range value of $7.0 \times$ $10^{-4} \mathrm{~m}$ for the aerodynamic roughness length of snow was taken from Michel (1971). A roughness length of $3.0 \times 10^{-4} \mathrm{~m}$ was assigned to the ice when free of snow (Michel, 1971).

Because of the differences in air content and crystal structure, the density and thermal properties of snow ice and secondary ice (black ice) differ as well. A density of $900 \mathrm{~kg} \mathrm{~m}^{-3}$ (2\% air bubble fraction) was chosen as representative of the entire ice layer. Corresponding values for thermal conductivity, $2.03 \mathrm{~W} \mathrm{~m}^{-1}{ }^{\circ} \mathrm{C}^{-1}$, and diffusivity, $1.07 \times 10^{-6} \mathrm{~m}^{2} \mathrm{~s}^{-1}$, were computed from Yen (1981). 


\section{RESULTS AND DISCUSSION}

Results from applying the simulation model to the 1980-81 season are shown in Figs. 3-7. In each case, the curve labeled "Model B" represents an application of the model that assumes a linear temperature gradient through the ice cover. The curve labeled "Model A" represents an application of the nonlinear temperature gradient model. The bottommost curve in each figure shows observed snow depth and duration at each site.

The two ice-thickness simulation curves generally bracket the observations, with the linear temperature gradient model (Model B) simulating a thicker ice cover. The one exception occurred at site G-2, which also experienced the greatest depth and duration of snow cover. This phenomenon will be discussed below. Although the slopes of the simulation curves mimic the trend of the observations, the simulations both underpredict and overpredict the end of an ice

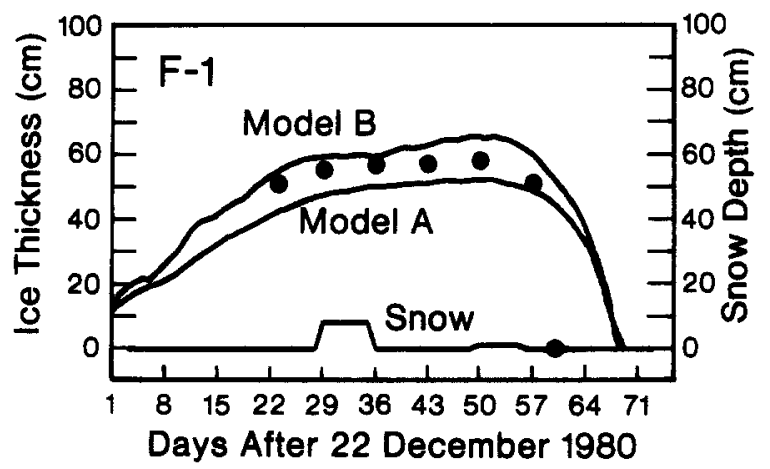

Fig. 3. Simulated ice growth and decay at site F-1.

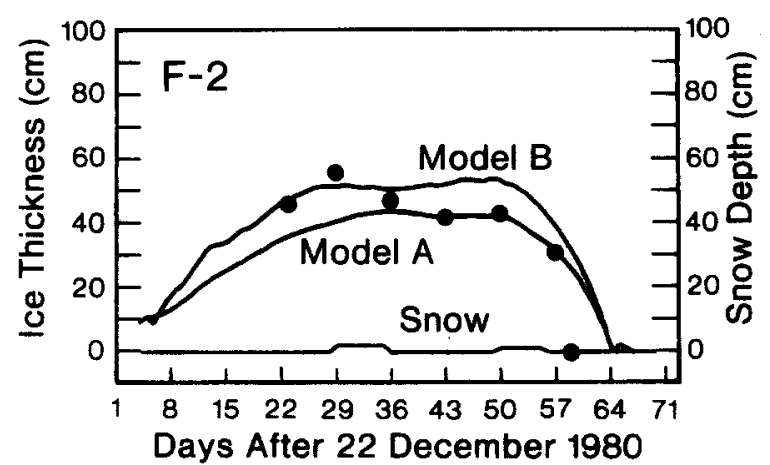

Fig. 4. Simulated ice growth and decay at site F-2. cover by 2-7 days. Some of the discrepancy may be caused by the difficulty of assigning the "observed" breakup date. It is more probable, however, that the lack of simulation of mechanical weakening, as well as thermal decay, causes the weaker fit of model to observations (Ashton, 1984).

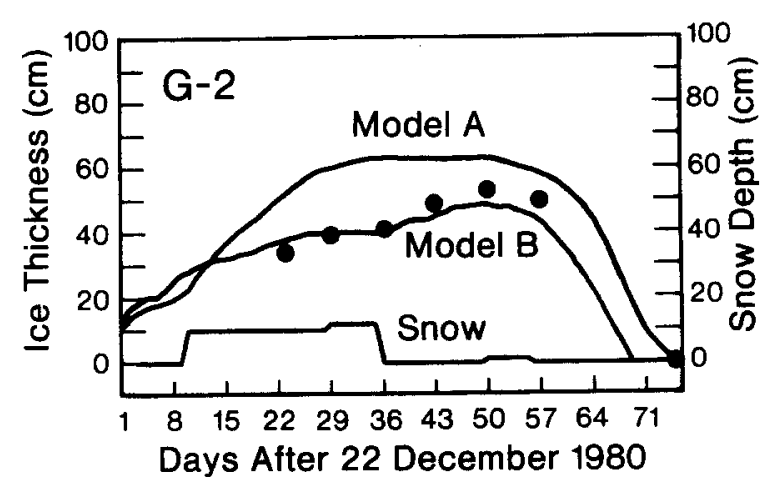

Fig. 5. Simulated ice growth and decay at site G-2.

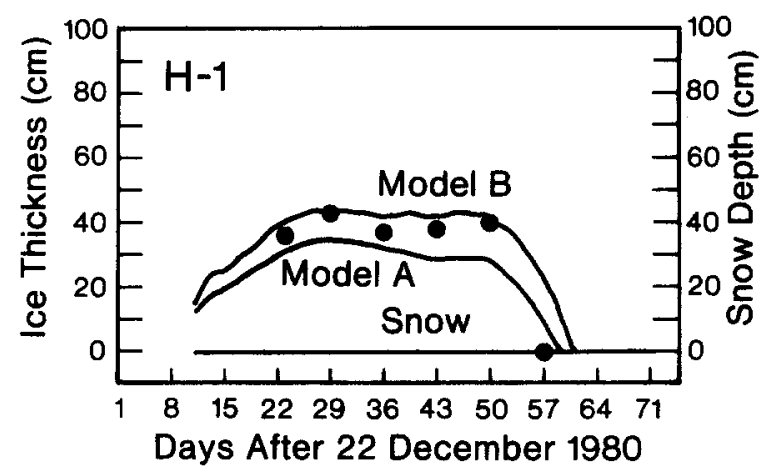

Fig. 6. Simulated ice growth and decay at site H-1.

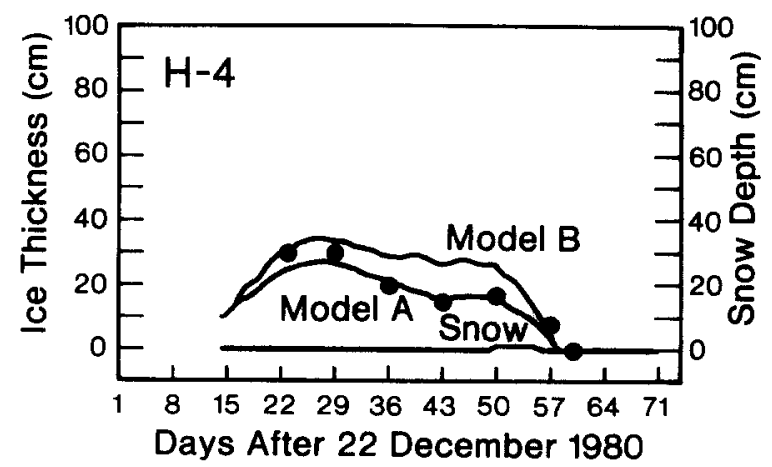

Fig. 7. Simulated ice growth and decay at site H-4. 
The difference in simulated ice-cover thickness in the two models is caused by differences in the simulated surface temperature. This difference is shown for station F-2 in Fig. 8, which depicts simulated surface temperatures, observed air temperature, and interpolated water temperature for the season.

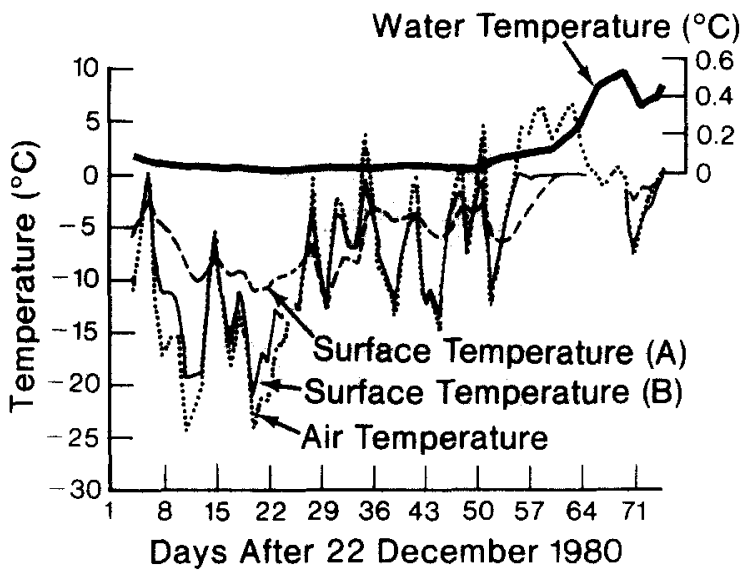

Fig. 8. Surface temperatures simulated by the two versions of the model. Observed air temperatures from Ogdensburg, N.Y., and water temperatures interpolated between Kingston, Ont., and Cornwall, Ont.

The simulated surface temperatures in the figure differ by as much as $9^{\circ} \mathrm{C}$ on any one date. The surface temperature produced by the linear gradient version of the model (model B) follows the air temperature quite closely, with the greatest differences occurring during the first 10 days of growth. Surface temperatures were also constrained at $0^{\circ} \mathrm{C}$ during spring melt.

The surface temperatures produced by the nonlinear temperature version of the model (model A) act like smoothed air temperatures except during the snow covered period. Unlike the linear gradient version of the model, the non-linear version has a "memory" of the previous day's temperature profile. In the linear gradient version, $Q_{\mathrm{i}}$ is computed by eqn. (10), where $T_{\mathrm{m}}$ is $0^{\circ} \mathrm{C}$ and $T_{\mathrm{s}}$ is the equilibrium temperature to be solved for. The previous $T_{\mathrm{s}}$ exerts an influence only in the sense that it affects the growth of the ice layer.

In contrast, eqn. (12), used to compute $Q_{\mathrm{i}}$ for the nonlinear version, includes the term $T_{\mathrm{s}-1}$ (the temperature at one node below the surface on the previ- ous day). Even if the nonlinear version produced a linear temperature gradient on a given day it could not, on the next day, produce a $T_{\mathrm{s}}$ that diverged by much since the increase in $Q_{\mathrm{i}}$ would have to be balanced by corresponding changes in $Q_{\mathrm{m}}, Q_{\mathrm{h}}$, and $Q_{\mathrm{le}}$.

As pointed out above, the nonlinear temperature gradient model (model $\mathrm{A}$ ) has an anomalous reaction to prolonged snow cover, as seen in Fig. 5 . The high growth rate of ice during this period is contrary to the expected insulating effects of the snow cover. The increased growth occurs because the simulated snow surface temperatures are cold enough to drop the temperature at the ice-snow interface to a temperature below that simulated at an ice surface without snow.

This phenomenon could be caused either by the choice of values assigned to snow properties or by the numerical method. As will be shown, the model is generally more sensitive to variations in system properties than to variations in forcing variables. In this case, however, the cause is more likely related to the use of a 24 -h time step. When the time interval is dropped to $1 \mathrm{~h}$, simulated maximum ice thickness at
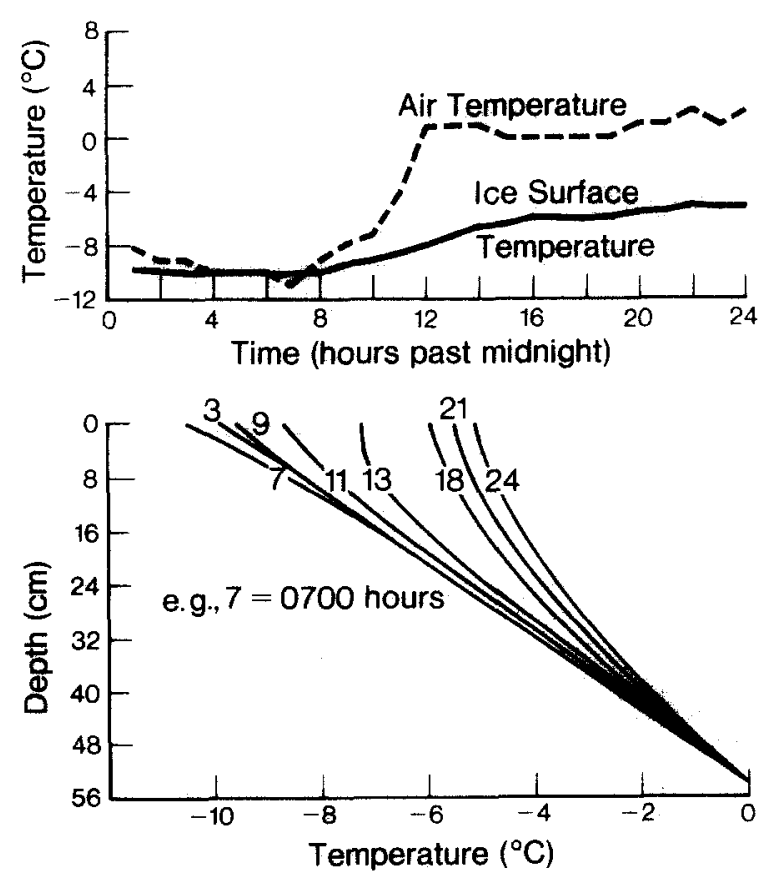

Fig. 9. Simulated evaluation of the thermal profile in $54 \mathrm{~cm}$ of ice, February 1, 1981. Upper curve shows observed air tem. perature and simulate surface temperature. Numbers on the lower curves denote time of day. 
station $\mathrm{F}-2$ is $8 \mathrm{~cm}$ less than the maximum ice thickness computed under no snow conditions.

An example of simulated temperature gradient change in a $54-\mathrm{cm}$-thick ice sheet is shown in Fig. 9. The upper curve in the top graph is the measured warming of the air on February 1, 1981, at a station adjacent to the St. Lawrence River at Ogdensburg. The lower curve in the top graph is the simulated temperature response of the snow-free surface of the ice sheet. The bottom graph shows the simulated internal temperature profiles over the same period. The temperature gradient is strongest at 7:00 a.m. At that time, it is also approximately linear. Over the course of the day, the upper portion of the ice sheet warms quickly, creating a nonlinear temperature gradient.

\section{MODEL SENSITIVITY}

Table 3 summarizes the effects of variation of model variables and parameters on the simulated maximum thickness and date of breakup for station F-2. The amount of variation was chosen to represent either the potential error in the measurement of a variable or a reasonable range of values for system properties. Some negative deviations, such as those in wind speed, had to be limited so that they would not fall below a zero value.

The algebraic signs of the departures are those one would expect. For example, the temperature curves in Fig. 8 shows that the simulated surface temperature was usually higher than the air temperature. An increase in wind speed or surface roughness should therefore cause a larger heat loss owing to turbulent transfer and a consequent increase in ice thickness. The largest departure, $6.5 \mathrm{~cm}$ for variation in the extinction coefficient, represents a $15 \%$ decrease from the standard run maximum thickness of 43.5 $\mathrm{cm}$. The date of breakup is relatively insensitive except to variations in water temperature.

While Table 3 allows one to quantify the effects of variations, it does not allow comparison between variables other than those of comparable units. A

TABLE 3

Nonlinear temperature gradient model sensitivity

\begin{tabular}{|c|c|c|c|}
\hline & \multirow[b]{2}{*}{. } & \multicolumn{2}{|c|}{ Departure from standard run values (F-2) } \\
\hline & & $\begin{array}{l}\text { maximum thickness } \\
(\mathrm{cm})\end{array}$ & $\begin{array}{l}\text { date of breakup } \\
\text { (days) }\end{array}$ \\
\hline \multicolumn{4}{|c|}{ Meteorological variables } \\
\hline \multirow{2}{*}{\multicolumn{2}{|c|}{$\begin{array}{l}T_{\mathrm{a}} \pm 1\left({ }^{\circ} \mathrm{C}\right) \\
U \pm 1\left(\mathrm{~m} \mathrm{~s}^{-1}\right)\end{array}$}} & $-1.8 /+2.4$ & $-1 /+1$ \\
\hline & & $+2.0 /-2.5$ & $+1 /-1$ \\
\hline \multicolumn{2}{|c|}{$T_{\mathrm{d}} \pm 2\left({ }^{\circ} \mathrm{C}\right)$} & $-0.1 / 0.0$ & $0 / 0$ \\
\hline \multicolumn{2}{|c|}{$Q_{\mathrm{sw}} \pm 1.0\left(\mathrm{MJ} \mathrm{m}^{-2} \mathrm{day}^{-1}\right)$} & $-0.4 /+1.0$ & $0 /+1$ \\
\hline \multicolumn{2}{|c|}{$Q_{1 \mathrm{w}} \pm 1.0\left(\mathrm{MJ} \mathrm{m}^{-2} \mathrm{day}^{-1}\right)$} & $-1.4 /+1.8$ & $-1 /+1$ \\
\hline \multicolumn{2}{|c|}{$T_{\mathrm{w}} \pm 0.1\left({ }^{\circ} \mathrm{C}\right)$} & $-3.5 /+4.4$ & $-2 /+2$ \\
\hline \multicolumn{4}{|c|}{ Snow and ice properties } \\
\hline$A$ & $\begin{array}{l}0.45 \pm 0.1 \text { (ice) } \\
0.85 \pm 0.1 \text { (snow) }\end{array}$ & $+2.6 /-2.5$ & $0 /-1$ \\
\hline$Z_{\mathrm{o}}$ ice & $\begin{array}{l}0.0003+0.0027(\mathrm{~m}) \\
0.0003-0.00027(\mathrm{~m})\end{array}$ & $+4.0 /-1.3$ & $0 /+1$ \\
\hline$k$ & $2.0 \pm 0.5\left(\mathrm{~m}^{-1}\right)$ & $-6.5 /+4.1$ & $0 / 0$ \\
\hline$K_{\mathfrak{i}}$ & $2.03 \pm 0.01\left(\mathrm{~W} \mathrm{~m}^{-1} \mathrm{C}^{-1}\right)$ & $+0.8 /-0.9$ & $0 /+1$ \\
\hline & $0.307 \pm 0.1\left(\mathrm{~W} \mathrm{~m}^{-1} \mathrm{C}^{-1}\right)$ & $-0.1 /+0.1$ & $0 / 0$ \\
\hline \multicolumn{2}{|c|}{$\begin{array}{l}U_{\mathrm{w}} \pm 0.20\left(\mathrm{~m} \mathrm{~s}^{-1}\right) \\
B_{\mathrm{i}} \pm 300\left(\mathrm{~W} \mathrm{~m}^{-2.6} \mathrm{~s}^{0.8}{ }^{\circ} \mathrm{C}^{-1}\right)\end{array}$} & $\begin{array}{l}-2.0 /+2.8 \\
-1.7 /+2.3\end{array}$ & $\begin{array}{l}-1 /+1 \\
-1 /+1\end{array}$ \\
\hline
\end{tabular}


method described by Coleman and DeCoursey (1976) was used to compute a parameter called the relative importance $(R D)$. If $X$ is any independent model variable and $Y$ is a dependent variable, such as ice thickness, $R I$ is found by

$R I=\left[(\Delta Y / \Delta X)\left(\left(X_{\max }-X_{\min }\right) / Y\right)\right]$.

Note that $R I$ is related to, but not the same as, relative sensitivity. By including the expected range of a variable, $R I$ becomes dimensionless and can be used to compare the effect of any independent variable with another. The relative importance was computed for both the positive and negative departure for each of the variables and then averaged. These values are listed in Table 4 by their ranking.

\section{TABLE 4}

Relative importance of model parameters, from most important to least important

\begin{tabular}{ll}
\hline Variable & Relative impact on maximum ice thickness \\
\hline$k$ & 0.122 \\
$T_{\mathrm{w}}$ & 0.091 \\
$Z_{\mathrm{o}}$ ice & 0.061 \\
$A$ & 0.059 \\
$U_{\mathrm{W}}$ & 0.055 \\
$U$ & 0.052 \\
$T_{\mathrm{a}}$ & 0.048 \\
$B_{\mathrm{i}}$ & 0.046 \\
$Q_{\mathrm{lw}}$ & 0.037 \\
$K_{\mathrm{i}}$ & 0.019 \\
$Q_{\mathrm{sw}}$ & 0.015 \\
$T_{\mathrm{d}}$ & 0.002 \\
$K_{\mathrm{s}}$ & 0.002 \\
\hline
\end{tabular}

The ranking of the model parameters demonstrates two features of the model: (1) the model is more sensitive to conditions beneath the ice $\left(T_{\mathrm{w}}, U_{\mathrm{w}}\right)$ than to the meteorological variables above the ice, and (2) the model is more sensitive to system parameters than to the forcing variables interacting with those properties. For example, the model is more sensitive to variations in the aerodynamic roughness length than to variations in wind speed. The low sensitivity to variations in the dew-point temperature is reasonable given the minor role of evaporation from ice. The model is also insensitive to variations in the thermal conductivity of the snow and ice.

\section{SUMMARY}

The growth and decay of the ice cover on a river manifest a complex series of heat transfer processes within and between different media. It is commonly acknowledged that many of these processes are selfcanceling in their effects, such that very simple models can reasonably reproduce observed rates of growth and decay. It is of interest, however, to examine more detailed simulations as a way of isolating significant properties or processes.

The model described here couples the simulation of upper and lower surface energy fluxes with the diffusion of heat through the ice sheet. For these processes, the model is more sensitive to changes in system properties than to changes in the forcing meteorological variables. However, it is the under-ice conditions, represented by water temperature and water velocity, that exert the greatest influence on simulated growth.

\section{ACKNOWLEDGMENTS}

The authors would like to thank Stephen Hung of St. Lawrence Seaway Development Corporation for his help in obtaining the meteorological data from Ogdensberg. Comments from the reviewers were of value in clarifying the use of the model. A portion of this work was done by the first author in partial fulfillment of the requirements for a Ph.D. degree in the Department of Geography, The University of Michigan.

\section{REFERENCES}

Anderson, E.A. and Baker, D.R. (1967), Estimating incident terrestrial radiation under all atmospheric conditions. Water Resour. Res., 3: 975-988.

Ashton, G.D. (1973), Heat transfer to river ice covers. In: Proc. East. Snow Conf., pp. 125-135. (Available from U.S. Army Cold Regions Research and Engineering Laboratory Library, Hanover, N.H.).

Ashton, G.D. (1978), River ice, Annu. Rev. Fluid Mech., 10: 369-392.

Ashton, G.D. (1979), Suppression of River Ice by Thermal Effluents. CRREL Report 79-30, Cold Regions Research and Engineering Laboratory, Hanover, N.H., 26 pp. Ashton, G.D. (1984), Deterioration of floating ice covers, 
In: V.J. Lunardini (Ed.), Proc. 3rd Int. Symp. on Offshore Mech, and Arctic Eng., New Orleans, February 1984.

Baines, W.D. (1961), On the transfer of heat from a river to an ice sheet. Trans. Eng. Inst. Can., 5: 27-32.

Beckett, R. and Hurt, J. (1967), Numerical Calculations and Algorithms. McGraw-Hill, New York, 295 pp.

Bolsenga, S.J. (1965), The relationship between total atmospheric water vapor and surface dew point on a mean daily and hourly basis. J. Appl. Meteorol., 4: 430-432.

Bolsenga, S.J. (1969), Total albedo of Great Lakes ice. Water Resour. Res., 5: 1132-1133.

Calkins, D.J. (1979), Accelerated Ice Growth in Rivers. CRREL Report 79-14, U.S. Army Cold Regions Research and Engineering Laboratory, Hanover, N.H., 4 pp.

Coleman, G. and DeCoursey, D.G. (1976), Sensitivity and model variance analysis applied to some evaporation and evapotranspiration models, Water Resour. Res., 12: 873-879.

Gates, D.M. (1962), Energy Exchange in the Biosphere. Harper \& Row, New York, 151 pp.

Greene, G.M. (1981), Simulation of Ice-cover Growth and Thermal Decay on the Upper St. Lawrence River. Ph.D. thesis, Department of Geography, The University of Michigan (Available from University Microfilms, Ann Arbor, Mich.), 142 pp.

Maguire, J.J. (1975), Light Transmission through Snow and Ice. Technical Bulletin 91, Canada Centre for Inland Waters, Burlington, Ont.

Maykut, G.A. and Untersteiner, N. (1971), Some results from a time-dependent thermodynamic model of sea ice. J. Geophys. Res., 76: 1550-1575.

Michel, B. (1971), Winter Regime of Rivers and Lakes. Monograph III-B1A, U.S. Army Cold Regions Research and Engineering Laboratory, Hanover, N.H., 130 pp.

Outcalt, S.I. and Carlson, J.H. (1975), A coupled soil thermal regime surface energy balance simulator. In: Proc. Conf. on Soil-Water Problems in Cold Reg., Special Task Force, Div. of Hydrol., Amer. Geophys. Union., Calgary, Alb., pp. 1-31.

Outcalt, S.I., Goodwin, C., Weller, G. and Brown, J. (1975), Computer simulation of the snowmelt and soil thermal regime at Barrow, Alaska. Water Resour. Res., 11: 709715.

Paulson, C.A. (1970), The mathematical representation of wind speed and temperature profiles in the unstable atmospheric surface layer. J. Appl. Meteorol., 9: 857861.

Shen, H.T. and Yapa, P.N.D.D. (1982), Winter Flow, Ice, and Weather Conditions of the Upper St. Lawrence River, 1971-81. Reports 82-1 (Part A) and 82-2 (Part B), Department of Civil and Environmental Engineering, Clarkson College, Potsdam, N.Y., 515 pp.

Shen, H.T. and Yapa, P.N.D.D. (1983), Simulation of the St. Lawrence River Ice Cover Thickness and Breakup. Report 83-1, Department of Civil and Environmental Engineering, Clarkson College, Potsdam, N.Y. 37 pp.

Wake, A. and Rumer, R.R., Jr. (1979), Modeling the ice regime of Lake Erie. J. Hydraulics Div., 105: 827-844.
Yen, Y.C. (1981), Review of the Thermal Properties of Snow, Ice, and Sea Ice. CRREL Report 81-10, U.S. Army Cold Regions Research and Engineering Laboratory, Hanover, N.H., 27 pp.

\section{APPENDIX}

\section{Energy balance at the upper boundary}

Energy balance at the ice-air interface must be considered under two conditions, with and without phase change. When no phase change is occurring, $T_{\mathrm{s}}$ is assumed to be less than $0^{\circ} \mathrm{C}$. During spring melt, the upper surface of the ice is melting and $T_{\mathrm{s}}$ is fixed at $0^{\circ} \mathrm{C}$. Considering the first case, one can assume that the flux of heat to the surface from below must equal the flux of heat leaving the ice surface under steady. state conditions

$Q_{\mathrm{s}}=-Q_{\mathrm{t}}$.

$Q_{\mathrm{t}}\left(\mathrm{W} \mathrm{m}^{-2}\right)$ is the sum of the relevant fluxes as defined by

$Q_{\mathrm{t}}=Q_{\mathrm{mn}}+Q_{\mathrm{h}}+Q_{\mathrm{k}}$

where $Q_{\mathrm{m}}$ is the net radiation flux, $Q_{\mathrm{h}}$ is sensible heat flux to the air, and $Q_{\mathrm{k}}$ is latent heat flux. The relevant equations for computing the net radiation flux and the turbulent transfer of sensible and latent heat are outlined below.

\section{Net radiation}

$Q_{\mathrm{m}}=(1-A) Q_{\mathrm{sW}}+\epsilon\left(Q_{\mathrm{I}}-\sigma T_{\mathrm{s}}^{4}\right)$

$Q_{\mathrm{rl}}=\sigma\left(T_{\mathrm{a}}\right)^{4}-\left[\left(110.6+5.41\left(\mathrm{e}_{\mathrm{a}}{ }^{0.5}-\mathrm{e}_{\mathrm{s}}^{0.5}\right)-0.485 E\right]\right.$ $\left(Q_{\mathrm{sw}} / Q_{\mathrm{swc}}\right)^{2}$

(Anderson and Baker, 1967; Bolsenga, 1965)

$Q_{\text {swc }}=Q_{\text {beam }}+Q_{\text {diff }}+Q_{\text {bacskt }}$

$Q_{\text {beam }}=Q_{\text {ext }} \exp \left(n_{\text {abs }}=n_{\text {abs }}=n_{\text {scat }}\right)$

(Gates, 1962)

$n_{\mathrm{abs}}=-0.089(P m / 1013)^{0.75}-0.174(w m / 20)^{0.6}$

(Gates, 1962)

$n_{\text {scat }}=-0.083(\mathrm{~d} m)^{0.9}$

(Gates, 1962) 


$$
Q_{\text {diff }}=0.5 Q_{\text {ext }}\left(1-\exp \left(n_{\text {scat }}\right)\right)
$$

(Outcalt and Carlson, 1975)

$Q_{\text {bacskt }}=0.5\left(Q_{\text {beam }}+Q_{\text {diff }}\right) A\left(1-\exp \left(n_{\text {scat }}\right)\right)$

(Outcalt and Carlson, 1975)

\section{Turbulent transfer}

$Q_{\mathrm{h}}=-\rho_{\mathrm{a}} c_{\mathrm{p}} v K^{2} U\left(T_{\mathrm{a}}-T_{\mathrm{s}}\right) / X$

$Q_{\mathrm{k}}=-\rho_{\mathrm{a}} \lambda \nu K^{2} U\left(q_{\mathrm{a}}-q_{\mathrm{s}}\right) / X$

$X=\left(\ln \left(Z_{\mathrm{a}} / Z_{\mathrm{o}}\right)-\psi_{1}\right)\left(\ln \left(Z_{\mathrm{a}} / Z_{\mathrm{o}}\right)-\psi_{2}\right)$,

where $\psi_{1}$ and $\psi_{2}$ are the Businger-Dyer functions (Paulson, 1970).

\section{LIST OF SYMBOLS}

\section{Capital letters}

\begin{tabular}{|c|c|}
\hline$A$ & Albedo \\
\hline$B_{\mathrm{i}}$ & $\begin{array}{l}\text { Constant used in eqn. (12) }\left(\mathrm{W} \mathrm{m}^{-2.6} \mathrm{~s}^{0.8}\right. \\
\left.{ }^{\circ} \mathrm{C}^{-1}\right)\end{array}$ \\
\hline C & Heat capacity $\left(\mathrm{J} \mathrm{m}^{-3}{ }^{\circ} \mathrm{C}^{-1}\right)$ \\
\hline$E$ & Station adjustment term for eqn. (A-2) \\
\hline$K$ & Thermal conductivity $\left(\mathrm{W} \mathrm{m}^{-1}{ }^{\circ} \mathrm{C}^{-1}\right)$ \\
\hline$P$ & Pressure $(\mathrm{mb})$ \\
\hline$Q$ & Heat flux $\left(W^{-2}\right)$ \\
\hline$Q_{\mathrm{h}}$ & Sensible heat flux to the air $\left(\mathrm{W} \mathrm{m}^{-2}\right)$ \\
\hline$Q_{\mathrm{le}}$ & Latent heat flux to the air $\left(\mathrm{W} \mathrm{m}^{-2}\right)$ \\
\hline$Q_{\mathrm{rl}}$ & $\begin{array}{l}\text { Downward atmospheric longwave radiation } \\
\text { flux }\left(\mathrm{W} \mathrm{m}^{-2}\right)\end{array}$ \\
\hline$Q_{\mathrm{m}}$ & Net radiation flux $\left(\mathrm{W} \mathrm{m}^{-2}\right)$ \\
\hline & Incident shortwave radiation flux $\left(\mathrm{W} \mathrm{m}^{-2}\right)$ \\
\hline$Q_{\text {swc }}$ & $\begin{array}{l}\text { Potential incident shortwave radiation flux } \\
\text { with no cloud cover }\left(\mathrm{W} \mathrm{m}^{-2}\right)\end{array}$ \\
\hline$Q_{\mathrm{t}}$ & Total net flux leaving the ice surface $\left(\mathrm{W} \mathrm{m}^{-2}\right)$ \\
\hline$Q_{\text {beam }}$ & Direct beam radiation flux $\left(\mathrm{W} \mathrm{m}^{-2}\right)$ \\
\hline$Q_{\text {diff }}$ & Diffuse radiation flux $\left(\mathrm{W} \mathrm{m}^{-2}\right)$ \\
\hline$Q_{\text {bacskt }}$ & Backscattered radiation flux $\left(\mathrm{W} \mathrm{m}^{-2}\right)$ \\
\hline$Q_{\text {ext }}$ & $\begin{array}{l}\text { Flux of shortwave radiation incident on a } \\
\text { horizontal surface "outside" the atmosphere } \\
\left(\mathrm{W} \mathrm{m}^{-2}\right)\end{array}$ \\
\hline$R$ & Hydraulic radius (m) \\
\hline
\end{tabular}

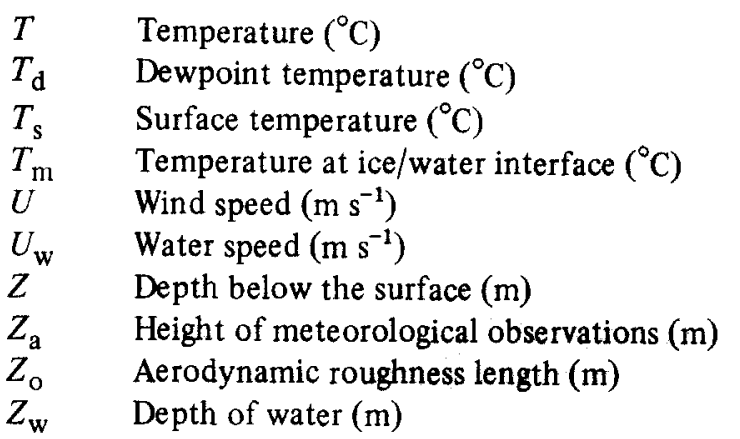

\section{Small letters}

$c_{\mathrm{p}} \quad$ Specific heat of air constant pressure $\left(\mathrm{J} \mathrm{kg}^{-1}\right.$ ${ }^{\circ} \mathrm{C}^{-1}$ )

d Atmospheric dust concentration (particles $\mathrm{cm}^{-3}$ )

$e_{\mathrm{a}} \quad$ Saturated vapor pressure at $\mathrm{T}_{\mathrm{a}}(\mathrm{mb})$

$e_{\mathrm{s}} \quad$ Saturated vapor pressure at $\mathrm{T}_{\mathrm{s}}(\mathrm{mb})$

$h_{\mathrm{i}} \quad$ Heat transfer coefficient from water to ice ( $w \mathrm{~m}^{-2}{ }^{\circ} \mathrm{C}^{-1}$ )

$k \quad$ Shortwave radiation extinction coefficient $\left(\mathrm{m}^{-1}\right)$

$m \quad$ Optical air mass

$n_{\text {abs }} \quad$ Absorption coefficient

$n_{\text {scat }} \quad$ Scattering coefficient

$q \quad$ Specific humidity $\left(\mathrm{kg} \mathrm{kg}^{-1}\right)$

$t \quad$ Time (s)

$\nu K \quad$ von Kármán constant

$w \quad$ Precipitable water $(\mathrm{mm})$

\section{Greek small letters}

$\alpha \quad$ Thermal diffusivity $\left(\mathrm{m}^{2} \mathrm{~s}^{-1}\right)$

$\epsilon \quad$ Longwave emissivity

$\lambda \quad$ Latent heat of fusion $\left(\mathrm{J} \mathrm{kg}^{-1}\right)$

$\rho \quad$ Density $\left(\mathrm{kg} \mathrm{m}^{-3}\right)$

$\sigma \quad$ Stefan-Boltzman constant (W $\left.\mathrm{m}^{-2} \mathrm{~K}^{-4}\right)$

$\psi \quad$ Businger-Dyer function

\section{Subscripts}

$\begin{array}{ll}\text { a } & \text { Air } \\ \text { i } & \text { Ice } \\ \text { s } & \text { Snow or surface (of ice or snow) } \\ \text { w } & \text { Water }\end{array}$

